New research reveals that media use may contribute to shaping not only adolescents' developing beliefs about gender, race, sexuality, and beauty ideals but also their brains and biology.

\title{
Children, Adolescents, and the Media: The Molding of Minds, Bodies, and Deeds
}

\section{Monique Ward}

Of the many forces shaping American youth, the media are both the most overrated and the most underrated. In response to tragedies such as school shootings or social problems such as rising obesity or teenage pregnancy rates, the media are often blamed as uniquely responsible. It is the violent video games and ubiquitous fast food commercials that have made our children violent and fat. In these instances, the media's role is overexaggerated, with more power being attributed to them than is appropriate. Research has shown that violence, obesity, and sexuality involve complex behaviors determined by multiple factors, among which media exposure is only one. On the other hand, when it comes to regular, everyday attitudes about the world, such as adolescents' beliefs about gender, race, and themselves, the media's role is often overlooked and underestimated. Less public attention has focused on how media use shapes young viewers' beliefs and behaviors in these domains. Yet emerging evidence indicates that the media-everything from television, movies, and magazines to music and the Internet-are likely to be one of the key forces contributing here as well.

Indeed, interest in the media's role in normative development of children and adolescents continues to grow, being led by research in public health, communication studies, medicine, and social and developmental psychology. Whereas new findings are emerging in traditional topics of study (such as media violence), other new work focuses on how media use affects the body, brain, and diverse behaviors. The goal of this chapter is 
to highlight new findings in four domains that offer greater understanding of the media's multifaceted implications for the lives of children and adolescents.

\section{Effects on Brain and Body: Looking Beyond Obesity}

A traditional concern about media use, and about TV viewing in particular, has been the relative passivity and inactivity inherent in their use. American children aged eight to eighteen are reported to use the media nearly eight hours each day, devoting three hours to TV viewing alone (Roberts, Foehr, Rideout, \& Brodie, 1999). In light of these patterns, concern has been raised that a high level of media use may contribute to the obesity epidemic we currently face. This concern has indeed proven to be warranted, with several studies indicating a significant correlation between greater amount of TV viewing and obesity (Crespo et al., 2001; Proctor et al., 2003; Robinson, 2001). For example, Dietz and Gortmaker (1985) found a significant association between time spent watching TV and the prevalence of obesity in three national samples of youths aged twelve to seventeen, even after controlling for prior obesity, race, socioeconomic status, and several other variables.

Yet, beyond issues of weight, new findings suggest other ways in which media use may affect the body. One new direction has been an examination of how media exposure affects the brain. Regardless of the content, exposure to television images has been found to stimulate the brain and thus may well shape its wiring and development. Supporting this notion, Christakis, Zimmerman, DiGiuseppe, and McCarty (2004) found that a greater level of TV viewing at ages one and three was associated with attention problems at age seven, even controlling for several possible confounds (for example, maternal education, cognitive stimulation in the home). This finding suggests possible links between early, extensive TV viewing and attention deficit or hyperactivity disorder, and it draws attention to the potential of TV use to train early-and also subsequent—brain functioning.

A related program of research is investigating the connection between viewers' hormonal level and their exposure to specific types of media. Previous work by Schultheiss and his colleagues demonstrated changes in participant hormonal level when feelings of power and affiliation were aroused. What type of experience and interaction arouses these feelings? To test whether media stimuli might be such a provocateur, Schultheiss, Wirth, and Stanton (2004) exposed participants to a thirty-minute clip from either The Godfather Part II or The Bridges of Madison County, chosen to arouse feelings of power or affiliation, respectively. Hormonal levels were tested from participants' saliva before and after viewing the clip and were also compared with levels from control participants. Data indicated significant changes in hormonal levels that varied by sex and experimental condition. After viewing the romantic film, men and women experienced a rise in their progesterone level relative to the control; men also experienced a dampening of 
their testosterone level. Change in testosterone level following exposure to The Godfather Part II clip depended on baseline level but increased greatly for men already high in testosterone. These findings indicate that media content can alter our endocrine environment, at least temporarily.

The implications for such an effect are extensive. For example, what more lasting changes might result from repeated viewing? What other content could provoke a hormonal response? Could early exposure to sexual images such as those seen in music videos trigger hormones involved in pubertal development (Ward \& Merriwether, personal communication)? Further study is needed to begin to untangle the diverse ways in which media use may affect our very biology.

\section{Me Versus Them: Media Effects on Beliefs About Gender and Race}

As noted earlier, whereas societal concern about media effects typically focuses on their shaping of behaviors, such as aggression, sexual risk taking, and unhealthy eating, media use is also likely to contribute to shaping children's beliefs about themselves and about others around them. One such area concerns basic beliefs about masculinity and femininity. Nearly every media portrayal, scene, and storyline conveys a message about "normative" and expected behaviors of women and men. From these portrayals, much can be learned about what types of women are considered attractive, which male behaviors draw scorn, and which life choices are rewarded. Yet, research finds that the frequently offered characterizations present a limited view of gender roles, relying heavily on stereotypes and one-dimensional characters (the ditz, the brute, and so on; for review, see Signorielli, 2001). With only a limited range of roles, looks, and behaviors presented and rewarded in the media, might children's beliefs about femininity and masculinity become equally constrained? Efforts to address this question in the 1970s and 1980s produced the expected results. Focusing on children's beliefs about women's place in the home versus the workforce, this early research documented both correlational and experimental links between heavy TV viewing and viewers' acceptance of stereotypical beliefs about gender (Signorielli, 2001; Ward \& Harrison, 2005).

Focusing on different yet related domains of gender, current findings continue to validate the importance of these connections. Drawing from stereotype threat theory, recent research by Davies, Spencer, Quinn, \& Gerhardstein (2002) demonstrates how exposure to media stereotypes can undermine women's confidence and performance. Female undergraduates exposed to stereotypical portrayals focusing on women's domesticity expressed less interest in quantitative careers, performed less well on a math test, and avoided math test items in favor of verbal items more so than did female students without this exposure. These findings offer disturbing indication of the detrimental power of negative media stereotypes. 
It is not just women who are at risk. Although much of the early work on media ideals and body image focused on the thin ideal and its effect on female viewers (Groesz, Levine, \& Murnen, 2002; Ward \& Harrison, 2005), increasingly, attention has focused on the effects of the muscular ideal on men's body image. Societal and media pressures regarding men's bodies have increased dramatically over the recent decade, with heavy emphasis on V-shaped bodies with broad shoulders; highly developed arm, chest, and abdominal muscles; and slim waists (Kolbe \& Albanese, 1996; Leit, Pope, $\&$ Gray, 2001). Research testing the impact of these stringent ideals finds that frequent readers of fitness magazines report greater body image dissatisfaction, drive for muscularity, and social physique anxiety (Duggan $\&$ McCreary, 2004; Morrison, Morrison, \& Hopkins, 2003). Moreover, experimental exposure to television images of the male body ideal led to greater dissatisfaction with their own musculature among undergraduate men (Agliata \& Tantleff-Dunn, 2004). Therefore, new evidence in multiple domains demonstrates a powerful connection between young viewers' media use and their gender and self-ideals.

A second domain of normative beliefs likely to be shaped by media use are those about race. In our highly segregated society, children's opportunities to interact with people of another ethnic group are often limited. This is especially true for whites, who live in neighborhoods that are on average 81 percent white (Frey $\&$ Myers, 2002). For many, then, the most regular "contact" with children from other ethnic groups may come through the media. Yet, what might repeated exposure to films such as Bringing Down the House, music videos from Snoop Dogg, and video games such as Grand Theft Auto teach white and minority youths about race? In these and other media outlets, only a small slice of African American and Latino Americans' lives are depicted as representative of the larger group, with this one slice focusing on gangster culture, crime, and sexual exploitation. Equally important, how might repeated exposure to such portrayals, or to those that totally exclude real people like them, make young minority viewers feel about themselves? This question is especially pressing given that black and Latino youths consume more media than their European American counterparts (Greenberg, Mastro, \& Brand, 2002) and may therefore be even more vulnerable to its stereotypical portrayals of race and gender.

Recent work has begun to address these concerns, illustrating that the nature of media effects on minority viewers depends on the form of media and type of viewer connection. For black youths, evidence suggests that media effects differ according to the student's exposure to and connections with black-oriented rather than mainstream media. Among black teens, Ward (2004) demonstrated that greater exposure to mainstream programming and stronger identification with white characters were each associated with lower self esteem, while stronger identification with popular black characters was associated with higher self-esteem. Similarly, Schooler, Ward, Merriwether, and Caruthers (2004) found that for black undergraduate 
women greater exposure to programming with predominantly white casts had virtually no effect on their body image whereas greater exposure to programming with predominantly black casts was associated with a more positive body image. These findings suggest that for black youths connecting to the few black media models available may offer some benefits, whereas emulating white models may be more detrimental to their self-conception.

The picture is less positive for Latino youths, however, who encounter few same-group portrayals (outside of Spanish-language programming). Indeed, current analyses indicate that Latinos make up only 6.5 percent of characters on prime-time TV, but 13 percent of the U.S. population (Children Now, 2004). Recent data indicate that among Latino high school and college students, frequent exposure to mainstream programming is associated with lower social self-esteem and lower appearance self-esteem (Rivadeneyra, Ward, \& Gordon, 2005). In addition, findings indicate that among Latino high school students exposure to mainstream TV and Spanishlanguage TV are both associated with greater endorsement of stereotypical gender roles, suggesting they receive a double dosage (Rivadeneyra and Ward, forthcoming). These findings are only a beginning. Further study is needed, especially work that examines Asian viewers, considers potential risk and protective factors, and asks how these portrayals shape young viewers' perceptions of other ethnic groups.

\section{From Beliefs to Behavior: Contributions of Media Sexual Content}

A third direction emerging from the field is renewed attention to the media as an agent of sexual socialization. Whereas it is often suggested that the media assume a prominent role in the sexual education of American youth, empirical evidence supporting this premise has been slow to accumulate. Much of the early work consisted either of content analyses documenting the frequency with which sexual references or acts occurred, or small-scale correlational analyses linking media exposure level and student sexual attitudes (for review, see Ward, 2003). In recent years, stemming from concerns about teenaged pregnancy, sexually transmitted infection, and human immunodeficiency virus, renewed attention has focused on possible connections between media use and adolescent sexual behavior. Five governmentsponsored, large-scale, longitudinal projects examining this issue are now ongoing (National Institute of Child Health and Human Development, 2000), and smaller, innovative work is under way on other fronts.

Emerging from these studies are consistent and surprising direct links between adolescent use of media and early sexual behavior. Focusing on participants' sexual media diets, Pardun, L'Engle, and Brown (2005) found that a greater level of exposure to movies and music high in sexual content was a significant predictor of young teens' participation in a range of sexual activities and of their intention to have sexual intercourse in the future. 
Similar results were reported by Ward and Friedman (under review), who found that greater exposure to music videos and talk shows, and stronger identification with popular media characters, each predicted a greater level of dating and sexual experience among high school students. Findings from longitudinal data add further strength to these associations. Specifically, Collins, Elliott, Berry, Kanouse, Kunkel, et al. (2004) found that in a national sample of 1,762 teens participant exposure to sexual content at time one was a strong, positive predictor of both their coital initiation one year later and more rapid progression through noncoital sexual activities (among virgins). Looking at more specific sexual behaviors, Wingood et al. (2003) discovered that frequent viewing of music videos at time one was linked with a larger number of sexual partners and higher likelihood of acquiring a new sexually transmitted disease one year later among black female adolescents. These findings paint a compelling picture of the association between adolescents' media use and their actual sexual behavior. To support this research, additional experimental work is needed, as are investigations testing how sexual content is interpreted, how it shapes viewers' perceptions of their sexual experiences, and whether it also affects their sexual communication and contraceptive use.

\section{Prevention and Intervention: Mediation and Entertainment Education}

With numerous findings documenting the negative impact of exposure to media violence and to stereotypical portrayals of race, gender, and sexuality, the question that often surfaces is, What positive and proactive steps can be taken to protect our children? Traditionally, responses have centered on the role of parental mediation and coviewing. Here, the notion is that having parents comment on appropriate and inappropriate content while watching TV with their children can help guide the influence of the messages. Although these constructs were initially discussed and tested in the 1970s and early 1980s, renewed attention to this approach and more rigorous experimental investigation demonstrate the benefits of such intervention. In one study, grade school children viewed four TV clips portraying stereotypical gender roles (Nathanson, Wilson, McGee, \& Sebastian, 2002). For children in one condition, the experimenter inserted comments contradicting the stereotypical behavior; in another condition, she did not. Results indicated that children in the mediation condition evaluated the program less positively and expressed greater acceptance of nontraditional gender roles for men than did children who received no mediation. Similar results have been obtained in experimental work testing children's responses to media violence (Nathanson, 2004).

However, because many teens consume television and other media in their bedroom (Roberts, et al., 1999), opportunities for this type of intervention may arise infrequently. What if prosocial messages were embedded 
in the content itself? Over the past five years, renewed effort has been given to testing the possible role of entertainment education, in which healthpromoting information is inserted by media makers into actual media storylines (for review, see Singhal \& Rogers, 1999). Such efforts have worked extremely well on the international front, offering soap opera viewers and listeners information about family planning and the importance of literacy education (Singhal \& Rogers, 1999). In the United States, the Centers for Disease Control and Prevention and the Kaiser Family Foundation have been working with TV producers to achieve similar outcomes. For example, when information about emergency contraception was included in one episode of ER, telephone surveys revealed a substantial increase in the number of regular ER viewers who could accurately define this method and explain how to access it (Kaiser Family Foundation, 2000). Similarly, when information about the effectiveness rate in condom use was incorporated into an episode of Friends, confirmed teen viewers were later more likely than nonviewers to provide accurate information about this statistic (Collins, Elliott, Berry, Kanouse, \& Hunter, 2003). These findings highlight the potential of mainstream entertainment media to increase young viewers' knowledge of important public health issues.

\section{Conclusion}

With their ability to amplify or neglect aspects of the social world, the American media are a potent socialization force. Although their influence is often either ignored or overblown, the findings summarized here indicate that neither perspective is entirely appropriate. Yes, some concerns about potential harmful consequences are warranted. Evidence indicates that frequent viewing of mainstream TV is associated with obesity, attention problems, body image dissatisfaction, a greater level of sexual experience, and lower self-esteem (among ethnic minority viewers). Findings from experimental paradigms highlight additional concerns, demonstrating that exposure to specific media stimuli can change viewers' hormonal level and decrease women's math performance. At the same time, however, we see that these connections are not guaranteed and do vary according to the specific media content and viewing audience. Indeed, media content infused with prosocial messages generates positive outcomes. Clearly, there are no easy answers to questions surrounding the nature of media influence; these are complex issues. Perhaps the trends highlighted in this review will encourage us all to stay tuned for future developments.

\section{References}

Agliata, D. \& Tantleff-Dunn, S. (2004). The impact of media exposure on males' body image. Journal of Social and Clinical Psychology, 23, 7-22.

Children Now. (2004). Fall colors: 2003-04: Prime time diversity report. Oakland, CA: Children Now. 
Christakis, D. A., Zimmerman, F. J., DiGiuseppe, D. L., \& McCarty, C. A. (2004). Early television exposure and subsequent attentional problems in children. Pediatrics, 113(4), 708-713.

Collins, R. L., Elliott, M. N., Berry, S. H., Kanouse, D. E., \& Hunter, S. B. (2003). Entertainment television as a healthy sex educator: The impact of condom-efficacy information in an episode of "Friends." Pediatrics, 112(5), 1115-1121.

Collins, R. L., Elliott, M. N., Berry, S. H., Kanouse, D. E. Kunkel, D. K., Hunter, S. B., \& Miu, A. (2004). Watching sex on TV predicts adolescent initiation of sexual behavior. Pediatrics, 114, e280-e289.

Crespo, C. J., Smit, E., Troiano, R. P., Bartlett, S. J., Macera, C. A., \& Andersen, R. E. (2001). Television watching, energy intake, and obesity in U.S. children. Archives of Pediatrics and Adolescent Medicine, 155, 360-365.

Davies, P., Spencer, S., Quinn, D., \& Gerhardstein, R. (2002). Consuming images: How television commercials that elicit stereotype threat can restrain women academically and professionally. Personality and Social Psychology Bulletin, 28, 1615-1628.

Dietz, W. H., \& Gortmaker, S. L. (1985). Do we fatten our children at the television set? Obesity and television viewing in children and adolescents. Pediatrics, 75, 807-812.

Duggan, S. J., \& McCreary, D. R. (2004). Body image, eating disorders, and the drive for muscularity in gay and heterosexual men: The influence of media images. Journal of Homosexuality, 47, 45-58.

Frey, W., \& Myers, D. (2002). Neighborhood segregation in single-race and multi-race America: A census 2000 study of cities and metropolitan areas. Washington, DC: Fannie Mae Foundation.

Greenberg, B. S., Mastro, D., \& Brand, J. E. (2002). Minorities and the mass media: Television into the 21 st century. In J. Bryant \& D. Zillmann (Eds.), Media effects: Advances in theory and research. Hillsdale, NJ: Erlbaum.

Groesz, L. M., Levine, M. P., \& Murnen, S. K. (2002). The effect of experimental presentation of thin media images on body satisfaction: A meta-analytic review. International Journal of Eating Disorders, 31, 1-16.

Kaiser Family Foundation. (2000). Teens and sex: The role of popular television. Fact sheet. Menlo Park, CA: Kaiser Family Foundation.

Kolbe, R. H., \& Albanese, P. J. (1996). Man to man: A content analysis of sole-male images in male-audience magazines. Journal of Advertising, 25(4), 1-20.

Leit, R. A., Pope, H. G., \& Gray, J. J. (2001). Cultural expectations of muscularity in men: The evolution of playgirl centerfolds. International Journal of Eating Disorders, 29, 90-93.

Morrison, T. G., Morrison, M. A., \& Hopkins, C. (2003). Striving for bodily perfection? An exploration of the drive for muscularity in Canadian men. Psychology of Men and Masculinity, 4(2), 111-120.

Nathanson, A. I. (2004). Factual and evaluative approaches to modifying children's responses to violent television. Journal of Communication, 20, 321-336.

Nathanson, A. I., Wilson, B. J., McGee, J., \& Sebastian, M. (2002). Counteracting the effects of female stereotypes on television via active mediation. Journal of Communication, 42(4), 922-937.

National Institute of Child Health and Human Development. (2000). Workshop on sex and the media. Bethesda, MD: National Institute of Child Health and Human Development.

Pardun, C. J., L'Engle, K. L., \& Brown, J. D. (2005). Linking exposure to outcomes: Early adolescents' consumption of sexual content in six media. Mass Communication and Society, 8(2), 75-91.

Proctor, M. H., Moore, L. L., Gao, D., Cupples, L. A., Bradlee, M. L., Hood, M. Y., \& Ellison, R. C. (2003). Television viewing and change in body fat from preschool to early adolescence: The Framingham children's study. International Journal of Obesity, 27, 827-833. 
Rivadeneyra, R., \& Ward, L. M. (in press). From Ally McBeal to Sabado Gigante: Contributions of television use to the gender role attitudes of Latino adolescents. Journal of Adolescent Research.

Rivadeneyra, R., Ward, L. M., \& Gordon, M. (2005). Distorted reflections: Media use and Latino adolescents' conceptions of self. Unpublished manuscript. Normal: Illinois State University.

Roberts, D., Foehr, U., Rideout, V., \& Brodie, M. (1999). Kids and media at the new millennium. Palo Alto, CA: Henry J. Kaiser Family Foundation.

Robinson, T. N. (2001). Television viewing and childhood obesity. Pediatric Clinics of North America, 48, 1017-1025.

Schooler, D., Ward, L. M., Merriwether, A., \& Caruthers, A. (2004). Who's that girl? Television's role in the body image development of young white and black women. Psychology of Women Quarterly, 28, 38-47.

Schultheiss, O. C., Wirth, M. M., \& Stanton, S. J. (2004). Effects of affiliation and power motivation arousal on salivary progesterone and testosterone. Hormones and Behavior, 46(5), 592-599.

Signorielli, N. (2001). Television's gender role images and contribution to stereotyping. In D. Singer \& J. Singer (Eds.), Handbook of children and the media (pp. 341-358). Thousand Oaks, CA: Sage.

Singhal, A., \& Rogers, E. M. (1999). Entertainment-education: A communicative strategy for social change. Mahwah, NJ: Erlbaum.

Ward, L. M. (2003). Understanding the role of entertainment media in the sexual socialization of American youth: A review of empirical research. Developmental Review, 23, $347-388$.

Ward, L. M. (2004). Wading through the stereotypes: Positive and negative associations between media use and black adolescents' conceptions of self. Developmental Psychology, 40, 284-294.

Ward, L. M., \& Friedman, K. (under review). Using TV as a guide: Associations between television viewing and adolescents' sexual attitudes and behavior. Journal of Research on Adolescence.

Ward, L. M., \& Harrison, K. (2005). The impact of media use on girls' beliefs about gender roles, their bodies, and sexual relationships: A research synthesis. In E. Cole \& J. H. Daniels (Eds.), Featuring Females: Feminist Analyses of Media. Washington, DC: American Psychological Association.

Wingood, G. M., DiClemente, R., Bernhardt, J., Harrington, K., Davies, S., Robillard, A., $\&$ Hook E. (2003). A prospective study of exposure to rap music videos and African American female adolescents' health. American Journal of Public Health, 93(3), 437-439.

L. MONIQUE WARD is associate professor of psychology at the University of Michigan. 